\title{
क्रणी
}

\section{O Perfil do Aluno da Educação a Distância e seu Estilo de Aprendizagem}

\author{
Mailson Alan de Godoi ${ }^{1}$, Sandra Maria da Silva Sales Oliveira*2
}

\begin{abstract}
1 Mestre em Educação, Universidade do Vale do Sapucaí. Av. Prefeito Tuany Toledo, 470 - Fátima, $37550-$ 000 - Pouso Alegre - MG - Brasil. alangodoi1@hotmail.com

2 Professora Doutora do Programa de Mestrado em Educação, Universidade do Vale do Sapucaí. Av. Prefeito Tuany Toledo, 470 - Fátima, 37550-000 - Pouso Alegre - MG - Brasil. smsso23@gmail.com
\end{abstract}

\section{Resumo}

O aluno da Educação a Distância possui características específicas. Quais são elas? Esta pesquisa buscou conhecer o perfil de alunos de graduação a distância e discutir o estilo de aprendizagem mais favorável para a sua formação. Desenvolver metodologias de ensino de acordo com o estilo de aprendizagem dos alunos incentiva o aprendizado com autonomia. Trata-se de uma pesquisa quantitativa, de caráter transversal e descritiva. Utilizou-se um questionário fechado com 20 perguntas. $\mathrm{O}$ instrumento foi aplicado por meio do software LimeSurvey. Os dados foram analisados por meio do software Statistical Package for the Social Sciences 18.0. A amostra é composta de 235 participantes, alunos de graduação de uma instituição de ensino superior privada localizada no Sul de Minas Gerais. Os resultados dos dados sociodemográficos mostraram que os alunos da Educação a Distância são, em sua maioria, do sexo feminino, com idade média de 33 anos e renda aproximada de três salários mínimos. A maioria estudou em escola pública, trabalha, tem compromissos familiares e não tem dificuldade para utilizar as tecnologias na aprendizagem. Por ser um público adulto, os métodos de ensino mais apropriados são a andragogia e a heutagogia. Além desses resultados, outras informações serão apresentadas neste relato de pesquisa.

Palavras-chave: Educação a Distância, Dificuldades tecnológicas, Estilos de aprendizagem. 


\title{
The profile Education Student Distance and Your Learning Style
}

\begin{abstract}
The student of distance education has specific characteristics. What are they? This research aimed to know the profile of undergraduate students to distance and discuss what the most favorable learning style for your training. Develop teaching methods according to the learning style of the students encourages learning with autonomy. This is a quantitative, transversal and descriptive character. We used a closed questionnaire with questions 20. The instrument was applied using the LimeSurvey software. Data were analyzed using the Statistical Package for Social Sciences software 18.0. The sample consists of 235 participants, undergraduate students of a private higher education institution located in southern Minas Gerais. The results of the demographic data showed that Distance Education students are mostly female, with a mean age of 33 years and with an approximate income of three minimum wages. Most studied in public school, work, have family commitments and has no difficulty to use the technology in learning. Being an adult audience, the most appropriate teaching methods are andragogy and heutagogy. In addition to these results other information will be presented in this research report.
\end{abstract}

Keywords: Distance Education, Technological difficulties, Learning styles. 


\section{Tendências da Educação a Distância}

Hoje existem estudos sobre as características e as estruturas da Educação a Distância (TORI, 2010; MENDES, 2012). Segundo a pesquisa da NMC Horizon Report: 2014 Higher Education Edition (JOHNSON et al., 2014), a qual investiga o futuro da tecnologia no ensino, a educação híbrida ou o blended learning é uma das tendências no aprendizado nos próximos anos por proporcionar o desenvolvimento de habilidades e competências nas pessoas. No entanto, é necessário conhecer quem é o aluno dessa modalidade.

Conhecer o aluno e como ele aprende torna-se crucial para definir qual o estilo de aprendizagem mais adequado para a modalidade a distância e, assim, desenvolver metodologias de ensino que favoreçam experiências de conhecimento. O objetivo desta pesquisa foi conhecer as características do aluno a distância no modelo e-learning e discutir qual o método de ensino mais favorável para a sua aprendizagem: se é a pedagogia, a andragogia ou a heutagogia.

Schnitman (2010) ressalta que conhecer o perfil do aluno da Educação a Distância contribui para o uso das tecnologias e colabora para a aprendizagem significativa por meio da definição do estilo de aprendizagem mais adequado. Para desenvolver políticas a favor da modalidade a distância e criar estratégias educacionais é necessário conhecer quem é o aluno que prefere estudar utilizando as tecnologias. Desse modo, é preciso responder às questões: qual o perfil do aluno de graduação a distância? Qual o método de ensino mais favorável para a sua aprendizagem?

Para responder a essas questões, buscou-se primeiramente entender os estilos de aprendizagem baseados na pedagogia, na andragogia e na heutagogia. Depois foram coletados dados sociodemográficos de alunos que estudam em um modelo elearning de Educação a Distância.

\section{Estilos de aprendizagem e a Educação a Distância}

O público de cursos a distância é específico. Geralmente são adultos com idade média de 30 anos, em sua maioria do gênero feminino, casados e trabalhadores (Fiuza, 2012; Martins et al., 2012; Aquino; Oliveira, 2013; Martins et al., 2013; Censo EaD, 2014). Lima, Sá e Pinto (2014) verificaram que a idade varia entre 18 e 33 anos. Para 
Martins et al. (2012), o número de mulheres na Educação a Distância está relacionado à predominância de cursos de licenciatura nessa modalidade, pois geralmente as mulheres procuram mais por cursos de docência do que os homens.

Sanchez (2011) relacionou os estilos de aprendizagem com planejamento de qualidade visando à retenção do aluno na Educação a Distância. A autora chegou à conclusão de que alguns indicadores de qualidade dos cursos podem contribuir para a permanência. O primeiro indicador de qualidade é a adequação dos estilos de aprendizagem de acordo com as especificidades tecnológicas da modalidade. $O$ segundo indica que a adequação do curso ao público-alvo, a linguagem a ser usada e a seleção das mídias a serem utilizadas também podem influenciar na retenção. $O$ último indica que implantar a metodologia da Andragogia de acordo com os estilos de aprendizagem pode contribuir para o sucesso do aluno. O último indicador refere-se à adequação das ferramentas tecnológicas para os cursos a distância e ao público-alvo. Esses aspectos devem ser levados em conta no planejamento de cursos a distância, a fim de contribuir para maior motivação dos alunos e criar ações para a permanência dos alunos na instituição de ensino.

Mendes (2012) ressalta que a Pedagogia centra a aprendizagem no professor, pois os alunos são dependentes, motivados extrinsecamente e têm dificuldades para desenvolver autonomia no conhecimento. A Pedagogia é a educação da criança e do adolescente, e no processo de aprendizagem quem define o que e como o aluno vai aprender é o professor (Martins, 2013).

Para Mendes (2012), a Andragogia está voltada para a educação adulta, público que tem condições de aprender sozinho, mas precisa conciliar os estudos com os outros compromissos diários. A Andragogia, embora encontre suas bases na Pedagogia, atribui ao aluno a responsabilidade pelo processo de aprendizagem (MENDES, 2012). Quem define o que aprender é o professor; no entanto, como a aprendizagem vai acontecer fica sob a responsabilidade do aprendiz (Sanchez, 2011).

Outro conceito ligado à Andragogia é a Heutagogia, termo que significa autocondução da aprendizagem (Peleias, 2013). As novas tecnologias, a virtualização da realidade e o conhecimento compartilhado permitem a autogestão da aprendizagem. Nesse sentido, é o aluno quem decide como aprender e o professor facilita este processo propondo situações e problemas, pois tanto o conteúdo como o processo de aprendizagem são definidos pelo aprendiz. 
Essa forma de educar também está muito presente na modalidade a distância; nela o aluno pode se guiar pelo conteúdo do curso e ampliar seus estudos por meio de pesquisas na internet e participação em grupos de discussão da web.

No entanto, somente disponibilizar o conteúdo para o aluno não é o suficiente. É necessário promover a sua autonomia por meio de suporte contextual. Nesse sentido, o curso deve ser planejado visando desenvolver a motivação discente.

Isler e Machado (2013) identificaram os fatores que influenciam a motivação para aprender na Educação a Distância. A motivação provém de três elementos: das características da personalidade do próprio aluno (autodeterminação e autorregulação de aprendizagem), da equipe envolvida na organização (tutores, professores e gestores, dentre outros) e dos recursos tecnológicos e didáticos disponíveis. Os autores ressaltam que os dois últimos elementos são fundamentais para a motivação.

Um aluno que não obtém as devidas respostas para as suas dúvidas no ambiente virtual de aprendizagem pode sentir-se desmotivado para aprender por não receber a devida atenção dos professores e dos tutores. Além disso, um aluno com dificuldades para usar as tecnologias e utilizar as ferramentas didáticas do curso pode sentir-se desmotivado no curso se não encontrar apoio suficiente para superar seus problemas. Portanto, não basta autogerir seu próprio aprendizado; mesmo na andragogia e na heutagogia o aluno necessita sentir-se motivado para desenvolver autonomia nos estudos.

Além da motivação proposta por Isler e Machado (2013), Mendes (2012) afirma que os estudantes necessitam de motivação para aprender na modalidade a distância. Nesse sentido, a organização do curso, sua estrutura, a concepção de Educação assumida e a gestão são aspectos que podem influenciar na aprendizagem do aluno. Ora, se as necessidades do aluno não são atendidas e se ele não encontra as condições necessárias para desenvolver autonomia, dificilmente vai conseguir assumir as rédeas de seu aprendizado. Por isso, esse aspecto na modalidade deve ser prezado pelos gestores da Educação a Distância.

Passano (2011) ressalta que a andragogia está baseada na aprendizagem por meio de solução de problemas, e sua prática não se contrapõe à pedagogia; elas se complementam. Peleias (2013) afirma que a Andragogia e a Heutagogia se interrelacionam com a Pedagogia, origem de toda a base conceitual para a criação de novas 
metodologias para os diferentes públicos. Martins (2013) salienta que a Andragogia se difere da Pedagogia em contraposição, mas ambas as ciências contribuem para a educação adulta.

Os autores apontam que a Andragogia e a Heutagogia são os métodos mais favoráveis para o estilo de aprendizagem de alunos a distância (Sanchez, 2011; Passano, 2011; Mendes, 2012; Peleias, 2013; Martins, 2013). No entanto, não basta confiar na autonomia para aprender, é necessário motivar o aluno (Sanchez, 2011; Mendes, 2012; Isler; Machado, 2013).

\section{Metodologia}

A pesquisa é quantitativa e de cunho descritivo e transversal. A coleta de dados foi realizada por meio da aplicação de um questionário sociodemográfico com 20 perguntas fechadas. A aplicação do instrumento foi via internet, por meio do software LimeSurvey. O link da pesquisa foi enviado para os alunos no ambiente virtual de aprendizagem por meio do correio eletrônico. Os dados foram colhidos no período de abril a julho de 2015 e, em seguida, foram disponibilizados numa planilha Excel. A análise dos dados foi feita por meio do software SPSS - Statistical Package for Social Sciences 18.0, o qual permitiu verificar as tendências maiores a partir das maiores médias das respostas.

A amostra da pesquisa é formada por 235 alunos da graduação a distância de uma instituição privada de Ensino Superior localizada no Sul de Minas Gerais. Entre os cursistas da instituição, havia 25 alunos que já possuíam graduação, 21 que já possuíam especialização lato sensu, 5 que já possuíam mestrado e 1 que já possuía doutorado.

A amostra foi selecionada por conveniência e compreende todos os alunos regulares. Os participantes pertencem aos cursos de licenciatura em Música (19,6\%), licenciatura em Pedagogia (14,5\%), licenciatura em Letras (12,8\%), bacharelado em Administração $(11,1 \%)$, licenciatura em Física $(11,1 \%)$, bacharelado em Engenharia Civil (9,8\%), bacharelado em Engenharia da Produção $(7,7 \%)$, bacharelado em Sistemas de Informação (7\%) e Licenciatura em Matemática (6,4\%). A maioria dos participantes está no primeiro período do curso $(28,5 \%)$, seguido pelo terceiro período $(25,5 \%)$ e pelo quinto período $(17,4 \%)$. 


\section{Resultados e discussão}

Os resultados estão divididos em quatro aspectos: informações gerais, informações financeiras/econômicas, informações educacionais e informações tecnológicas. Os resultados ficaram bem próximos de pesquisas já realizadas sobre 0 perfil do aluno da Educação a Distância (Martins et al., 2012; Martins et al., 2013; Aquino; Oliveira, 2013; Censo EaD, 2014). Isso mostra que realmente o aluno dessa modalidade tem características específicas, como podemos verificar na Tabela 1:

Tabela 1. Informações gerais de alunos da Educação a Distância

\begin{tabular}{|c|c|c|}
\hline Idade média & Participantes & 33 \\
\hline \multirow[t]{2}{*}{ Gênero } & Feminino & $54,5 \%$ \\
\hline & Masculino & $45,5 \%$ \\
\hline \multirow[t]{4}{*}{ Estado civil } & Casado & $49,4 \%$ \\
\hline & Solteiro & $40,8 \%$ \\
\hline & Divorciado & $9,8 \%$ \\
\hline & Viúvo (a) & $0,0 \%$ \\
\hline \multirow[t]{6}{*}{ Situação familiar } & Com marido/esposa ou companheiro(a) e filhos & $33,0 \%$ \\
\hline & Com pais ou parentes & $33,0 \%$ \\
\hline & Com marido/esposa ou companheiro(a) (sem filhos) & $19,0 \%$ \\
\hline & Com filho(s) & $8,5 \%$ \\
\hline & Sozinho(a) & $5,0 \%$ \\
\hline & Com amigos ou conhecidos & $1,5 \%$ \\
\hline
\end{tabular}

Esses resultados vão ao encontro da pesquisa de Fiuza (2012), na qual a idade média dos participantes foi de 32,3 anos; $64 \%$ dos participantes eram mulheres; $60,7 \%$ eram casados; e 38\% moravam com marido/esposa ou companheiro(a) e filhos. Em Martins et al. (2012), a faixa etária média foi de 30 anos, a maioria era mulher (70,3\%). Martins et al. (2013), pesquisando sobre evasão, encontraram um grupo maior de alunos com idade próxima aos 30 anos e agrupamentos menores com idades inferiores a 21 anos ou superiores a 40 anos. Essas informações coincidem com 
o Censo EaD (2014), em que a idade média é de 30 anos ou mais e 57,5\% dos cursistas totalmente a distância são mulheres.

Essa idade mais adulta pode interferir nos estudos dos alunos, pois o fato de serem mais velhos, casados e com filhos indica a existência de várias responsabilidades profissionais e familiares além dos estudos. As dificuldades em encontrar tempo para se dedicar podem interferir no desempenho acadêmico. Todavia, mesmo com essas dificuldades, deve-se reconhecer os benefícios da Educação a Distância para esse público e o caráter flexível e inclusivo da modalidade (Censo EaD, 2014).

Como podemos ver na Tabela 2, a maioria trabalha. A hipótese é que ela encontra na Educação a Distância uma possibilidade de continuar seus estudos e se capacitar.

Tabela 2. Informações financeiras/econômicas

\begin{tabular}{|c|c|c|}
\hline Renda familiar & $\begin{array}{r}\text { Entre } R \$ 1.001,00 \text { e } R \$ 2.000,00 \\
\text { Entre } R \$ 2.001,00 \text { e } R \$ 3.000,00 \\
\text { Entre } R \$ 3.001,00 \text { e } R \$ 4.000,00 \\
\text { Acima de } R \$ 6.000,00 \\
\text { Entre } R \$ 500,00 \text { e } R \$ 1.000,00 \\
\text { Entre } R \$ 4.000,00 \text { e } R \$ 5.000,00 \\
\text { Entre } R \$ 5.001,00 \text { e } R \$ 6.000,00 \\
\text { Menos de } R \$ 500,00\end{array}$ & $\begin{array}{r}28,10 \% \\
26,00 \% \\
11,10 \% \\
10,60 \% \\
10,20 \% \\
7,70 \% \\
4,30 \% \\
2,00 \%\end{array}$ \\
\hline \multirow[t]{2}{*}{ Empregado } & Sim & $75,3 \%$ \\
\hline & Não & $24,7 \%$ \\
\hline \multirow{3}{*}{$\begin{array}{l}\text { Dispensa para } \\
\text { estudar (dos } \\
\text { empregados) }\end{array}$} & Não, eu estudo no meu tempo de folga & $68,0 \%$ \\
\hline & Sim, fui dispensado pela empresa para estudar & $19,8 \%$ \\
\hline & $\begin{array}{r}\text { Não, mas posso usar parte do meu horário de } \\
\text { trabalho para o estudo }\end{array}$ & $12,2 \%$ \\
\hline \multirow{5}{*}{$\begin{array}{l}\text { Quem paga o curso a } \\
\text { distância atual }\end{array}$} & Eu mesmo(a) & $73,0 \%$ \\
\hline & Outra pessoa da família & $12,5 \%$ \\
\hline & Bolsista & $10,2 \%$ \\
\hline & Eu e a empresa & $3,4 \%$ \\
\hline & A empresa & $0,4 \%$ \\
\hline
\end{tabular}

A faixa média de renda familiar dos alunos está entre $R \$ 1.001,00$ e $R \$ 2.000,00$ $(28,1 \%)$ e entre $R \$ 2.001,00$ e $R \$ 3.000,00$ (26\%). Essas rendas podem ser 
consideradas baixas para os alunos casados que precisam pagar o curso e sustentar uma família. Martins et al. (2012) encontraram renda de até 3 salários mínimos, e Bittencourt e Mercado (2014) entre 3 a 5 salários mínimos em alunos evadidos. Fiuza (2012) relacionou a boa renda familiar ao bom desempenho na Educação a Distância.

A maioria dos participantes está empregada (75,3\%), e a renda familiar variou bastante, mas verifica-se que existem alunos cuja renda familiar é inferior a $\mathrm{R} \$ 500$ por mês $(2,0 \%)$, valor considerado insuficiente para suprir as necessidades de uma família e consequentemente as despesas de um estudante em instituição privada. Assim como aparece em Fiuza (2012), o Censo EaD (2014) também verificou que a maioria dos alunos estuda e trabalha.

A maioria não é dispensada pela empresa para fazer o curso (68\%). O curso é pago pelo próprio aluno (73\%), pois poucos relataram receber ajuda de empresas para estudar. Esses resultados coincidem com o achado de Fiuza (2012), em que a maioria não é dispensada pelas empresas para estudar ou realizar os encontros presenciais e paga os próprios cursos. Isso mostra que a melhor opção para o aluno que trabalha é realizar um curso a distância, por possibilitar adaptação do tempo e permitir a realização de suas obrigações familiares e profissionais.

Na Tabela 3 observam-se as informações escolares dos participantes. Esse aspecto pode ser relacionado tanto com os dados econômicos/financeiros como com as dificuldades de aprendizagem.

Como visto, a renda familiar dos alunos não é alta; portanto, supõe-se que a maioria estudou em escola pública. O fato de ter menor renda também pode impactar no desenvolvimento de habilidades tecnológicas, pois o acesso à tecnologia pode mais difícil. 
Tabela 3. Informações educacionais

\begin{tabular}{l|r|r}
\hline Ensino básico & Escola pública & 82,5 \\
& Escola particular & 10,2 \\
& Ensino Fundamental em escola pública e Ensino Médio & 4,7 \\
em escola particular & em escola pública & 2,6 \\
\hline Escolaridade & Ensino Fundamental em escola particular e Ensino Médio & em \\
& Cursando graduação & 76,2 \\
\hline $\begin{array}{l}\text { Realização de outro } \\
\text { curso a distância }\end{array}$ & Pós-graduação lato sensu/Especialização & 10,6 \\
\hline $\begin{array}{l}\text { Conclusão de outros } \\
\text { cursos a distância }\end{array}$ & Pós-graduação stricto sensu/Mestrado & 8,9 \\
& Cursando Pós-graduação & 2,1 \\
\hline & Pós-graduação stricto sensu/Doutorado & 1,7 \\
\hline
\end{tabular}

Esses resultados vão ao encontro dos achados de Martins et al. (2012), em que a maioria dos participantes também estudou em escola pública. Na pesquisa de Fiuza (2012), a maioria também estava cursando a graduação (57,5\%). Apesar de a Educação a Distância ser um pouco desconhecida, pois $71,1 \%$ nunca fizeram outro curso a distância antes do atual, essa modalidade pode possibilitar às pessoas a realização do sonho de se formar no Ensino Superior. Dos 28,9\% que já tinham feito um curso a distância, 70,3\% concluíram, o que indica baixa evasão nos cursos realizados por esses alunos antes de entrar na instituição.

Em Fiuza (2012), a maioria também nunca tinha feito outro curso a distância a não ser o atual. Isso pode ser sinal de que os alunos desconhecem a aplicabilidade das tecnologias na aprendizagem por nunca terem estudado na modalidade. Essas informações tecnológicas encontram-se na Tabela 4. 
Tabela 4. Informações tecnológicas

\begin{tabular}{l|r|r}
\hline $\begin{array}{l}\text { Computador de uso } \\
\text { pessoal }\end{array}$ & Sim & 100,0 \\
\hline Frequência de acesso à & Não & 0,0 \\
\hline internet & Diário & 98,3 \\
& Semanal & 1,7 \\
\hline $\begin{array}{l}\text { Tipo de acesso à } \\
\text { internet }\end{array}$ & Quinzenal & 0,0 \\
& Mensal & 0,0 \\
\hline & Discado & 94,9 \\
& ADSL & 2,1 \\
& Celular & 1,5 \\
\hline $\begin{array}{l}\text { Habilidade com } \\
\text { tecnologia }\end{array}$ & Rádio & 1,5 \\
& Cabo & 0,0 \\
\hline Dificuldades para usar & Satélite & 0,0 \\
\hline $\begin{array}{l}\text { as tecnologias na } \\
\text { aprendizagem }\end{array}$ & Experiente & 62,6 \\
\hline & Iniciante & 29,7 \\
\hline & Expert & 7,7 \\
\hline
\end{tabular}

A conexão mais comum é a discada (94,9\%). Esse dado parece ser estranho, visto que hoje em dia a conexão à internet mais comum é a ADSL, que é uma conexão mais rápida. Pode ser que os alunos não tenham sabido distinguir o tipo de sinal de internet, mesmo o questionário oferecendo uma explicação de cada item. Em Fiuza (2012), a internet mais comum entre os alunos é a ADSL, e eles usam o computador em casa. O Censo EaD (2014) verificou que a banda larga (internet via ADSL ou a cabo) é a internet mais comum entre as instituições ofertantes de cursos a distância.

Martins et al. (2012) também constataram que a maioria dos alunos têm computador em casa e acesso a internet, apesar de 8,8\% declararem não possuir computador. Em Bittencourt e Mercado (2014), todos os participantes evadidos têm acesso à internet: $45 \%$ em casa, $45 \%$ no trabalho e $10 \%$ em lan houses; somente $2 \%$ 
têm internet discada, o que pode dificultar o acesso ao ambiente virtual por ser uma conexão mais lenta.

Sobre o nível de habilidade com as tecnologias, 62,6\% consideram-se experientes e 49,4\% não têm dificuldades em usar as tecnologias na aprendizagem. Vale ressaltar que $29,7 \%$ relataram ser iniciantes e $17 \%$ declararam ter dificuldades com as tecnologias na aprendizagem. Isso pode estar relacionado ao baixo número de alunos que já fizeram outro curso a distância antes do atual (71,1\%). Dos que iniciaram outros cursos, 70,3\% concluíram, o que mostra baixa evasão. Em Martins et al. (2013), a educação a distância também era novidade para a maioria dos alunos.

Aquino e Oliveira (2013) encontraram alguns alunos com dificuldade em usar as tecnologias (5\%). Lima, Sá e Pinto (2014) salientam que alunos calouros geralmente sentem dificuldade para usar as tecnologias na aprendizagem, não conseguem organizar o tempo e focar nas atividades do ambiente virtual de aprendizagem. Isso pode prejudicar o aproveitamento do curso e causar evasão.

Fiuza (2012) constatou que a habilidade com as tecnologias pode aumentar em até 97\% o desempenho do aluno a distância. Martins et al. (2013) afirmam que as dificuldades em usar as tecnologias podem se tornar fatores de evasão. Por isso, é importante um suporte tecnológico ao aluno.

\section{Considerações finais}

Este trabalho buscou pesquisar o perfil dos alunos da Educação a Distância de uma instituição de ensino superior privada do Sul de Minas Gerais e o estilo de aprendizagem mais adequado para esse público. Os resultados deste estudo foram ao encontro das pesquisas já realizadas sobre o perfil do aluno da Educação a Distância (Fiuza, 2012; Martins et al., 2012, 2013; Aquino; Oliveira, 2013; Censo EaD, 2014).

O perfil do aluno é formado por pessoas adultas, trabalhadoras e com compromissos familiares. O público é constituído predominantemente por mulheres. Essas características mostram que o público da Educação a Distância é específico, pois as pessoas procuram estudar nessa modalidade em busca de flexibilidade e conciliação, o que é o caso de pessoas mais velhas e casadas, as quais têm mais compromissos familiares e de trabalho do que os jovens. 
Essas características específicas dos alunos a distância vão ao encontro da proposta de Sanchez (2011), Mendes (2012), Passano (2012) e Peleias (2013), os quais afirmam que os métodos de ensino como a Andragogia e a Heutagogia atendem às necessidades e capacidades desse público.

No entanto, Isler e Machado (2013) lembram que a motivação é um aspecto importante para a aprendizagem. Assim, somente propor o conteúdo para o aluno e confiar a ele todo o processo de aprendizagem pode não ser motivador, visto que o ele precisa interagir e sentir-se motivado para fazer as atividades. Além disso, um professor-tutor pode motivar o aluno a desenvolver autonomia nos estudos.

Outros estudos com amostras maiores e envolvendo instituições privadas e públicas devem ser realizados para maior compreensão da problemática sobre o perfil do aluno da Educação a Distância e o estilo de aprendizagem adequado para a sua formação acadêmica. A criação de um questionário específico sobre o estilo de aprendizagem pode trazer respostas mais certas sobre a forma de aprender desse público.

Vale ressaltar que, apesar de as informações apresentadas irem ao encontro da literatura, os dados estão limitados a um contexto específico, pois não envolveu outras instituições de ensino, sejam públicas ou privadas. Por isso, os resultados não podem ser generalizados, até pelo tamanho da amostra. Outra limitação do estudo é o método de análise de dados e a não correlação entre os aspectos. Para um novo trabalho, propõe-se a análise anova, comparando as médias de resposta da variável curso.

Todavia, essas limitações do estudo não diminuem a importância da investigação sobre a temática. A pesquisa indica que os métodos de ensino como a Andragogia e a Heutagogia são favoráveis para a aprendizagem do aluno na Educação a Distância, modalidade que exige maior autonomia no processo de construção do conhecimento. Os adultos conseguem aprender sozinhos e, segundo as pesquisas de Isler e Machado (2013), são mais motivados a estudar.

\section{Referências bibliográficas}

Aquino, F. S.; Oliveira, A. P. (2013). O perfil do aluno de educação a distância do curso de licenciatura em Letras espanhol do polo de Marcelino Vieira. In IX Congresso 
de Iniciação Científica do IFRN (IX Congic) (pp. 2.037-2.046). Natal, RN. Disponível em

http://www2.ifrn.edu.br/ocs/index.php/congic/ix/paper/viewFile/800/261

Associação Nacional de Educação a Distância (2014). Censo EAD.BR: relatório analítico da aprendizagem a distância no Brasil 2013. São Paulo: Pearson Education do Brasil. Disponível em

http://www.abed.org.br/censoead2013/CENSO EAD 2013 PORTUGUES.pdf

Bittencourt, I. M.; Mercado, L. P. L. (2014). Evasão nos cursos na modalidade de educação a distância: estudo de caso do Curso Piloto de Administração da UFAL/UAB. Ensaio: aval. pol. públ. Educ., 22 (83), 465-504. Disponível em http://www.scielo.br/pdf/ensaio/v22n83/a09v22n83.pdf

Fiuza, P. J. (2012). Adesão e permanência discente na Educação a Distância: investigação de motivos e análise de preditores sociodemográficos, motivacionais e de personalidade para o desempenho na modalidade. Tese de doutorado. Universidade Federal do Rio Grande do Sul. Disponível em https://www.lume.ufrgs.br/bitstream/handle/10183/55089/000855707.pdf?sequ ence $=1$

Isler, G. L. ; Machado, A. A. (2013). Motivação discente em cursos na modalidade de educação à distância (EaD): fatores que influenciam. Revista Nupem, 5 (9), 6784. Disponível em http://www.fecilcam.br/revista/index.php/nupem/article/viewFile/270/259

Johnson, L. et al. (2014). NMC Horizon Report: 2014 Higher Education Edition. Austin: The New Media Consortium. Disponível em http://cdn.nmc.org/media/2014nmc-horizon-report-he-EN-SC.pdf> Acesso em: 20 de abr. 2015

Lima, M. A. de A.; Sá, E. M. O.; Pinto, A. de C. (2014). Perfil e dificuldades do aluno da EaD: o caso do curso de bacharelado de Administração Pública. In XI Congresso Brasileiro de Ensino Superior a Distância (XI Esud) (pp. 2.732-2.747). Florianópolis, SC. Disponível em http://esud2014.nute.ufsc.br/anaisesud2014/files/pdf/128198.pdf 
Martins, R. M. K. (2013). Pedagogia e Andragogia na construção da educação de jovens e adultos. Revista de Educação Popular, 12 (1), 143-153. Disponível em http://www.seer.ufu.br/index.php/reveducpop/article/view/20331/12520

Martins, R. X. et al. (2012). O perfil sociodemográfico de candidatos a cursos de licenciatura a distância e os objetivos da Universidade Aberta do Brasil. IX Congresso Brasileiro de Ensino Superior a Distância (IX Esud) (pp. 1-12). Recife, PE. Disponível em http://www.cead.ufla.br/portal/wpcontent/uploads/2012/10/IXESUDat1-completoroneiludmilalucianamarina.pdf

Martins, R. X. et al. (2013). Por que eles desistem? Estudo sobre a evasão em cursos de licenciatura a distância. X Congresso Brasileiro de Ensino Superior a Distância (X Esud) (pp. 1-15). Belém, PA. Disponível em http://www.cead.ufla.br/portal/wp-content/uploads/2013/08/XESUDat1-evasaoem-licenciaturasEAD-final.pdf

Mendes, Mônica Campos et al. (2012). Andragogia, métodos e didática do Ensino Superior: novo lidar com o aprendizado do adulto na EaD. Revista Eletrônica Gestão \& Saúde. 1 (1), 1.366-1.377. Disponível em http://gestaoesaude.unb.br/index.php/gestaoesaude/article/view/349

Passano, M. del P. A. (2011). Andragogía, educación durante toda la vida. Editorial Ver. Urug. Cardiol. 26 (3), 171-172. Disponível em http://www.scielo.edu.uy/pdf/ruc/v26n3/v26n3a01.pdf

Peleias, S. B. I. R. (2013). Em vez de dar o peixe, ensine a pescar: a Heutagogia e a sua relação com os métodos de aprendizagem em cursos EaD no Brasil. In IV Encontro de Ensino e Pesquisa em Administração e Contabilidade (IV Anpad) (pp. 1-14). Brasília, DF. Disponível em http://www.anpad.org.br/diversos/trabalhos/EnEPQ/enepq 2013/2013 EnEPQ1 48.pdf

Sanchez, L. (2011). Estilos de aprendizagem e planejamento de indicadores de qualidade para a retenção do aluno e diminuição da evasão na Educação a Distância. In D. M. V. Barros (Org.). Estilos de aprendizagem na atualidade. Lisboa: UAB Portugal (pp. 1-16). Disponível em http://www.metacognicao.com.br/wp-content/uploads/2012/11/EBook Completo Estilos de Aprendizagem.pdf 
Schnitman, I. M. (2010). O perfil do aluno virtual e as teorias de estilos de aprendizagem. In III Simpósio Hipertexto e Tecnologias na Educação (pp. 1-10). Recife, PE. Disponível em http://nehte.com.br/simposio/anais/Anais-Hipertexto2010/Ivana-Maria-Schnitman.pdf

Tori, R. (2010). Educação sem distância. São Paulo: Editora Senac, 2010. Disponível em http://pt.slideshare.net/romerotori/tori-educao-sem-distncia 